Western University Scholarship@Western

1987

\title{
Social Security, Longevity, and Moral Hazard
}

Peter Kuhn

James B. Davies

Follow this and additional works at: https://ir.lib.uwo.ca/economicsresrpt Part of the Economics Commons

Citation of this paper:

Kuhn, Peter, James B. Davies. "Social Security, Longevity, and Moral Hazard." Department of Economics Research Reports, 8706. London, ON: Department of Economics, University of Western Ontario (1987). 


\title{
ISSN : $0318-725 \mathrm{X}$ \\ ISBN : 0-7714-0855-2
}

\author{
RESEARCH REPORT 8706 \\ SOCTAL SECURITY, LONGEVITY, \\ AND MORAL HAZARD \\ Peter Kuhn \\ James B. Davies
}

\author{
Department of Economics \\ University of Western Ontario \\ London, Ontario, Canada
}

N6A $5 C 2$

April 1987

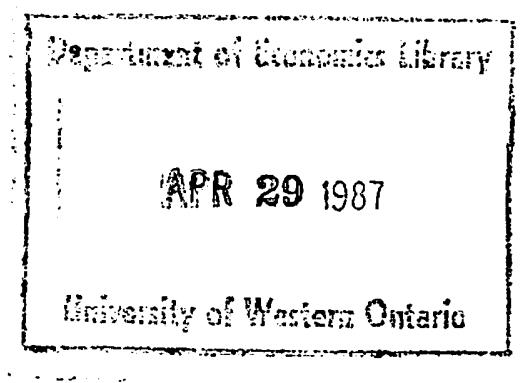


SOCIAL SECURITY, LONGEVITY, AND MORAL HAZARD

\author{
by \\ Peter Kuhn \\ and \\ Jim Davies
}

We would like to thank Dan Hamermesh, Dan Usher, and David Winch for helpful comments. Responsibility for any errors or omissions is our own.

March, 1987 


\section{"Social. Securdty Longevity, and Moral Hazari" \\ by Foter Kuhn and James E. Thutes}

$\operatorname{spri1} 7.987$

\section{: Pibetract}

Analysis of the jmpact of govenment poljey on longuvity is

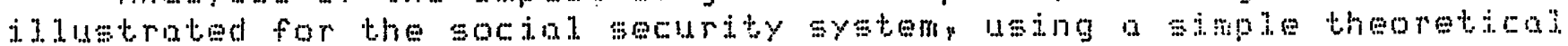

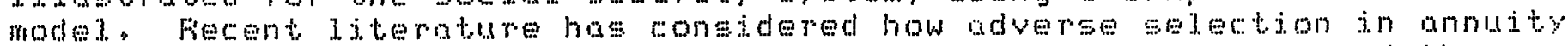

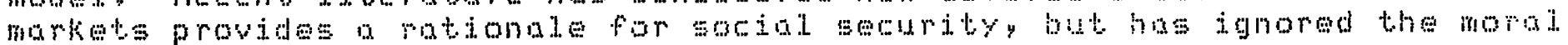

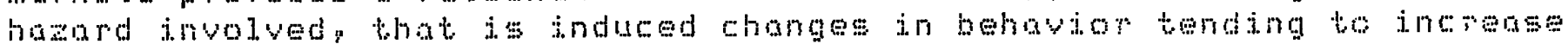
longovity. Here individuals consume a heath-related good which may. either inerease or reduce 1 ongevity A conpetitive annutit market an the absence

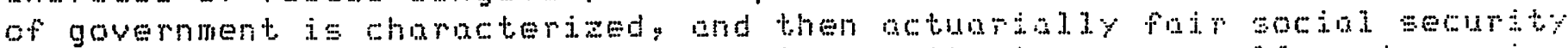

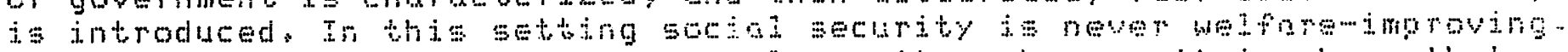
Fu most cases it tonds to encourage longevity whereas it is shown that

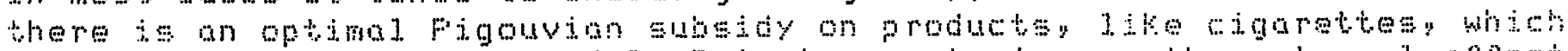

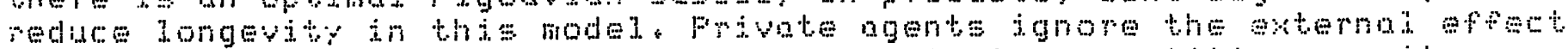

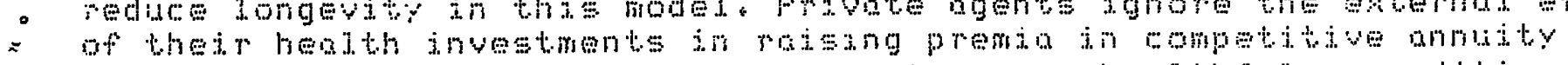

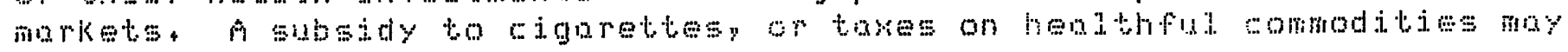
correct this distortion. 


\section{INTRODUCTION}

It is commonly recognized that a close relationship exists between the life expectancy of the U.S. population and the costs of several major federal government programs, including social security and medicare. Indeed, recent rapid increases in longevity ${ }^{1}$ have been at least partly responsible for certain "crises" in the financing of these programs. 2

Economic analyses of social security, medicare, and related policies have proliferated in recent years (in the case of social security, consider for example Feldstein (1976), Diamond (1977), Abel (1984, 1985) Kotlikoff et al (1983, 1984), and Eckstein et al (1985)) and embody a great variety of alternative assumptions. But one assumption which, to our knowledge, is shared by all these analyses is that of exogenous longevity. In other words, longevity and the changes that have occurred therein is treated as being determined by factors outside the economic system that is modelled.

Is the exogenous-longevity assumption a reasonable one in the analysis of the effects of programs like social security? Several possible justifications for this approach can be given, one of which argues that the actions individuals can take to influence their own life expectancies are rather limited. This reasoning, however, contradicts an extensive and rapidly-growing epidemiological literature which documents the extensive effects of lifestyles on longevity (see Barer et al (1984) for a recent summary). It also contradicts a long theoretical and empirical literature in economics which views individuals as making rational decisions affecting their own risk of death. Such decisions include the choice of job safety (Marin and Psacharopoulos, 1982), product safety and the consumption of hazardous goods (for example cigarettes--Harris 1980, Lewit and Coate 1982, Arnott, Lewis, and Olewiler 1986--), education and the acquisition of health-augmenting knowledge 
and skills (Taubman and Rosen, 1982), expenditures of time and money on medical services (Auster et al, 1969), choice of neighbourhood safety and enivronmental quality, the age of retirement (Wolfe, 1985), consumption habits such as diet and exercise, and the extreme case of suicide (Hamermesh and Soss, 1974). Given that the mortality effects of virtually each of these decisions, taken separately, have been sufficient to attract serious theoretical and empirical attention, then surely it is likely that, taking them all together, individuals have considerable control over their own longevity.

Another possible justification of exogenous longevity argues that, while (within strict biological constraints) individuals are able to affect their own longevity, such decisions are best analysed on sociological, or psychological grounds. In evaluating this argument, it is perhaps instructive to consider recent developments in the analysis of the other main demographic processes in any society: fertility, marriage, and migration. All of these were once thought to be outside the purview of economics, but now form important parts of economic theory and empirical work, partly as a result of Becker's (1981) pioneering research. It seems highly unlikely that the same will not turn out to be true of mortality.

A final possible justification for treating longevity as exogenous, at least in the study of effects of policies like social security, is the notion that there are no obvious "incentive" effects of these programs on longevity choices. For the case of social security, which is a kind of compulsory annuity, this is clearly false. By taxing individuals when young and only "refunding" the proceeds to them to the extent they live beyond a certain age, very strong and clear longevity incentives are created. Indeed, almost by definition, any program whose costs are significantly increased when longevity 
rises is likely to contain such incentive effects, since individual benefits will increase with years of life.

Given all the above arguments for endogenizing longevity in the study of government policy effects, such an analysis seems long overdue. This paper attempts such an analysis by choosing a particular policy - the social security system - and developing a simple, formal theoretical model of its effects on longevity. By focusing on the effects of social security on longevity, we also fill an important gap in the recent literature on social security. To see this, note that, given uncertain lifetimes, social security can be thought of as a kind of publicly - provided insurance against the event of an unexpectedly long life. Like all insurance, this is likely to be subject to two kinds of incentive problems: adverse selection and moral hazard. The first of these problems has been studied by Abel (1984) and Eckstein et al (1985); the latter is analysed for the first time, to our knowledge, in this paper. ${ }^{3}$

The paper proceeds as follows. Section II sets up a basic model of annuity markets in which an individual's consumption of a health-related good affects his or her expected longevity. By analysing optimal individual decisions we show that three different kinds of health-related goods arise naturally as special cases of the model. This structure gives the analysis added empirical content relative to the existing models of optimal investment in health (Grossman (1972), Muurinen (1982), Berkowitz et al (1983), and Wolfe (1985)), some of which endogenize longevity as well, but none of which consider individual responses to policies like social security.

Section III derives equilihrium conditions for competitive annuity markets characterized by moral hazard, and then analyses the effect of 
introducing an actuarially fair social security system into these markets. In doing, so it focuses on a single generation in isolation and on a particular class of health-related goods, typified by cigarettes, which yield relatively unambiguous results. Section IV extends the analysis to the other two types of health-related goods while section $V$ considers social security schemes that are not actuarially fair for some individuals. Some complications that may arise when the model is put into a full, overlapping-generations framework are discussed in Section VI. Section VII concludes.

The paper's main results concerning the impact of social security are the following. First, in contrast to the results of adverse-selection models, given that the state cannot observe or manipulate individuals' health behaviors better than private insurers, mandatory social security is never welfare-improving when the only imperfection is moral hazard in annuity markets. ${ }^{4}$ Second, for actuarially fair schemes the direction of the effect of social security on equilibrium investments in health depends on the type of health behavior examined, and is not always necessarily in the "intuitive" direction of promoting "too much" longevity. This is because of "income effects" arising from Social security taxation. Third, the effects of social security on longevity are unambiguously positive for the following kinds of individuals: (1) those who receive benefits, but pay no social security taxes and purchase no private annuities, regardless of the kind of health investments considered, and (2) those who pay some social security taxes, if their investments in health take the form of lower consumption of hazardous goods like cigarettes, or of financially costless changes in behavior, such as increased consumption of medical care in countries where it is free (1ike Canada and the U.K.). These results suggest that, at least in some situations, the social security system may have induced increases in longevity 
that have raised program costs, and may actually have lowered social welfare through this mechanism.

\section{BASIC STRUCTURE}

We consider an economy composed of a large number of identical individuals who live for a maximum of two periods, and focus initially on a single generation in isolation. There is no altruism; thus if there were no uncertainty, each individual would leave a bequest of zero. All members of a given generation are alive for certain in the first period of their lives, and survive with probability $\rho\left(A_{1}\right)$ into the second period, where $A_{1}$ represents the consumption level of a health-related good, $A$, in the first period. Since A can in principle also be consumed in the second period, a representative individual's expected lifetime utility is in general given by:

$$
W=U\left(x_{1}, A_{1}\right)+\rho\left(A_{1}\right) U\left(x_{2}, A_{2}\right)
$$

where $x_{i}$ represents consumption of all other goods in period $i$. We assume that $\frac{\partial U}{\partial x_{i}}>0, \frac{\partial^{2} U}{\partial x_{i}^{2}}<0, \frac{\partial U}{\partial x_{i}} \rightarrow \infty$ as $x_{i} \rightarrow 0$, and that the function $U$ is strictly concave. Individuals' consumption sets are also bounded by:

$$
0 \leq A_{i} \leq \bar{A}_{i}, i=1,2
$$

where $\bar{A}_{i}$ is maximum feasible consumption of $A$ in period $i$.

Individuals in this economy all earn an exogenous amount, $Y$, in the first period, which can be spent on consumption of both $x$ and $A$ in the first 
period or can be used to finance consumption of both goods in period 2, when earnings are zero. In the absence of government, there are two ways an individual can transfer resources to the second period in the model. 5 First, $R$ dollars of second-period income can be purchased by simply saving $\delta R$ dollars, where $\delta=\frac{1}{1+r}$. This is meant to represent a simple storage or production technology, with a fixed rate of return, $r \geq 0$. It is natural to impose $R \geq 0$, which we do throughout the paper. ${ }^{6}$ Alternatively, an individual can purchase an annuity contract which guarantees $B$ dollars of retirement consumption to the individual if he survives, by paying a premium of $P$ dollars in the first period. Annuity contracts are assumed to be supplied by competitive firms which simply collect premiums from young people, store the proceeds using the economy's linear storage technology, and redistribute the proceeds to survivors. Firms are assumed to be large enough that the annuity payout per surviving worker, B, can be treated as nonrandom, but competitive enough to require actuarial fairness, or zero profits:

$$
P(A) \delta B=P
$$

The fact that firms offer annuity contracts $(P, B)$ rather than sell annuities at a fixed price per unit results from our assumption that an individual's total annuity purchases are observable by the firm. This mitigates the moral hazard problem arising from the fact that firms do not observe individuals' purchases of health-related goods, A, but does not eliminate it. ${ }^{7}$ We assume also, initially, that negative annuities are infeasible. This is justified in Section III below, where we show that no such contracts will be offered in 
equilibrium, even when excessive annuities are provided by the social security system.

In the presence of a fixed, nonnegative annuity contract $(P, B)$, each individual in this economy thus solves:

$\underset{1, A_{2}, R}{\operatorname{Max}} W=U\left[Y-P-\delta R-P A_{1}, A_{1}\right]+\rho\left(A_{1}\right) U\left[R+B-P A_{2}, A_{2}\right]$

subject to: $0 \leq A_{i} \leq \bar{A}_{i}, i=1,2$

and to: $\quad R \geq 0$.

where $p$ is the price of a unit of $A$. This maximization problem may be written, using the indirect utility function $U^{2}(R+B)$ to suppress $A_{2}{ }^{8}$, in the simpler form:

$\operatorname{Max}_{A, R} W=U^{1}(Y-P-\delta R-P A, A)+\rho(A) U^{2}(R+B)$

$$
\begin{aligned}
& \text { subject to } 0 \leq A \leq \bar{A} \\
& \text { and to } R \geq 0 .
\end{aligned}
$$

where we have defined $A \equiv A_{1}, U^{1} \equiv U$, and for future reference will define $C_{1} \equiv x_{1}$ and $C_{2} \equiv R+B$. Throughout the remainder of the paper, (5) will be used to represent the maximization problem faced by all consumers in the economy.

Ignoring temporarily the inequality constraints, the first-order conditions for optimal $A$ and $R$ in (5) are simply:

$$
\begin{aligned}
& \frac{\partial W}{\partial A}=-p U_{C}^{1}+U_{A}^{1}+\rho^{1} U^{2}=0 \\
& \frac{\partial W}{\partial R}=-\delta U_{C}^{1}+\rho U_{C}^{2}=0
\end{aligned}
$$


We now note that, if individuals are to make a nontrivial (i.e. interior), choice of health-related goods, A, in the first period, then given without loss of generality ${ }^{9} \mathrm{p} \geq 0$, and ignoring goods with no effect on health $\left(p^{\prime}=0\right)$ the remaining terms in (6) can only assume three different sign patterns at the optimum. These patterns are given in Table 1, and correspond to three different types of health-related goods whose labels are given there.

All goods which yield positive direct marginal utility but increase the risk of death (at the margin) are included in Case 1. Examples are cigarettes, high-cholesterol foods, prolonged exposure to the sun, a low-fiber diet, dangerous sports like skydiving and automobile racing, sugar for

\section{TABLE 1: TXPES OF HEALTH-RELATED GOODS}

$\begin{array}{lcc} & \begin{array}{c}\text { Sign of } U_{A}^{\prime} \\ \text { at optimum }\end{array} & \text { Sign of } \rho \\ \text { Case } 1 \text { ("cigarettes") } & >0 & <0 \\ \text { Case } 2 \text { ("nutrition") } & >0 & >0 \\ \text { Case } 3 \text { ("doctors") } & \leq 0 & >0\end{array}$

diabetics, salt for hypertensives, and some illicit drugs. Case 2 goods yield direct utility and increase health (but are not consumed at maximal amounts because they are costly). They likely include, at lower levels of income, the basic nutrients, clothing and shelter. More generally they also include a wide range of sports and enjoyable forms of exercise, as well as (perhaps) leisure, in the form of earlier retirement (i.e. at some time before the first period ends) or shorter hours of work. The purchase of a home in a pleasant and healthful or crime-free environment might also be included here. Finally, Case 3 considers health-promoting activities ${ }^{10}$ which yield zero or negative 
direct utility at the optimum. These probably include visits to the doctor, purchases of prescription drugs, certain forms of exercise, investments in health-related knowledge, as well as working on a less dangerous but less renumerative job. ${ }^{11}$

Throughout the paper we make assumptions about the interaction between A and $C$ in the period-1 utility function which seem natural to the application at hand. Specifically, we assume that, when $U_{A}>0$ (Cases $I$ and 2), then $U_{A C}$ $\geq 0$. This is sufficient to ensure that, in the absence of any effects of $A$ on health, A would be a normal good. Similarly, when $U_{A}<0$, we assume $U_{A C}$ $\leq 0$, which ensures that $A$ is a "normal bad" in the following sense: Suppose an individual was consuming some of a bad because it was costly to remove. Then $A$ is a normal bad if his consumption of $A$ falls with his income. The above assumptions, while stronger than normality per se, are also stronger than what is needed to generate the predictions below. They do, however, lend some very useful intuition and are retained throughout for that reason.

III. KARKET EQUILIBRIUY AND THE EFFECTS OF SOCIAL SECURITY: THE "BASE CASE"

The most unambiguous theoretical results concerning the effect of actuarially fair social security on health are obtained in Case 1 above - the "cigarettes" model. This "base case" thus serves as a useful reference point for further elaborations and is examined in detail here. We consider, in turn (1) the first-best (full-information) private annuity-market equilibrium, (2) two distinct types of actual, second-best market equilibria, and then (3) the effect of introducing mandatory public social security into each of the two equilibria considered in (2). 


\section{First Best (Full-Information) Private Annuities}

Suppose that firms could observe, not only each individual's total annuity purchases but the level of health-related activity, A, that each person undertakes. (For the remainder of this section, we can think of $A$ as the number of cigarettes smoked.) Then firms can make receipt of any annuity conditional on the "right" level of A being chosen, and competition will require all firms to offer the utility-maximizing annuity contract. Thus the first best market annuity (and the associated private saving by consumer.s ${ }^{12}$ ) solves:

$$
\begin{aligned}
\operatorname{Max}_{A, R, B} W= & U^{1}[Y-\rho(A) \delta B-\delta R-P A ; A]+\rho(A) U^{2}[R+B] \\
& \text { s.t. } R \geq 0, B \geq 0 .
\end{aligned}
$$

It is easy to show that $R=0$ and $B>0$ at the maximum of ( 8$)$. This is because saving, which involves "wasting" resources on involuntary bequests, always has a lower rate of return than any actuarially fair annuity. Thus the first-best market annuity is fully characterized by the first-order conditions:

$$
\begin{aligned}
& \frac{\partial W}{\partial A}=-U_{C}^{1} \delta B \rho-p U_{C}^{1}+U_{A}^{1}+\rho^{1} U^{2}=0 \\
& \frac{\partial W}{\partial B}=-\rho \delta U_{C}^{1}+\rho U_{C}^{2}=0
\end{aligned}
$$

Aside from $R=0$ (no private saving is ever optimal) the first-best market equilibrium has two other important properties, apparent from (9) and (10). First, the optimal level of $A$ balances the financial and health costs 
of smoking ( $p \mathrm{U}_{\mathrm{C}}^{1}$ and $-\rho^{\prime} \mathrm{U}^{2}$ respectively) against two benefits, one direct and the other indirect. These two benefits are, respectively, the induced reduction in the market price of annuities that occurs if everyone smokes more $\left(-U_{C}^{1} \delta B \rho^{\prime}\right)$ and the direct utility of smoking $\left(U_{A}^{1}\right)$. Second, the optimal level of $C_{1}$ relative to $C_{2}$ in the presence of first-best annuity markets simply equates the ratio of marginal utilities of "consumption" to the discount factor, inherent in society's storage technology:

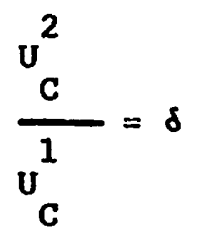

Thus, in a certain sense second-period consumption is not curtailed because of the risk of not surviving; indeed if there is a positive return to saving ( $r>0$, hence $\delta<1$ ) we will have $u_{C}^{2}<u_{C}^{1}$.

\section{Second-best (Asymmetric Information) Market Annuities}

We now relax the assumption that firms can observe individuals' choices of $A$ and replace it by the assumption that annuity contracts cannot depend explicitly on either $A$ or on $R$, the level of private saving undertaken by the consumer. ${ }^{13}$ In this world, competitive firms will offer the utilitymaximizing actuarially fair annuity contract $(P, B)$, subject to the constraints that individuals will choose the privately-optimal level of $A$ and of $R$ in response to this contract. We shall henceforth summarize these constraints by the first-order conditions for optimal $A$ and $R$, given the level of $P$ and $B$, which are just equations (6) and (7).

Second-best market annuities, and the associated level of private savings, thus satisfy: 


$$
\begin{gathered}
\underset{A, R, B}{\operatorname{Max}} W=U^{1}[Y-\rho(A) \delta B-\delta R-P A ; A]+\rho(A) U^{2}[R+B] \\
\text { subject to: } \frac{-p U_{C}^{1}+U_{A}^{1}+\rho^{1} U^{2}=0,}{-\delta U_{C}^{1}+\rho U_{C}^{2}}=0(\text { if } R>0),
\end{gathered}
$$

and to: $\quad R \geq 0, B \geq 0$.

Logically, four types of optima of (12)-(14) can exist, given by the cases $R=$ $0, B=0 ; R>0, B=0 ; R=0, B>0 ;$ and $R>0, B>0$. Before considering the properties of alternative equilibria, we first establish the convenient result that only the last two of these cases can occur. This is implied by:

Proposition 1 Annuity markets will never completely disappear in the second-best market equilibrium. That is, B >0 always.

Proof The impossibility of both $R=0$ and $B=0$ is easily ruled out by noting that private saving is always feasible and that, by assumption $U_{C}^{2} \rightarrow \infty$ as $c_{2} \rightarrow 0$. (See note 8 ).

To rule out the $R>0, B=0$ equilibrium, consider a world in which, initially, annuities are prohibited $(P=0, B=0)$ but consumers save and choose health optimally. Given $B=0$, the level of $R$ in this world will be determined uniquely by the individual-optimization constraints (13) and (14), for $A$ and $R$ respectively. Now consider introducing an infinitesimal, fully funded annuity, $d B$, into this world. Differentiating (12) with respect to $B$ yields: 


$$
\begin{aligned}
\frac{\partial W}{\partial B} & =\left[-\delta U_{C}^{1}+\rho U_{C}^{2}\right] \frac{d R}{d B}+\left[-U_{C}^{1} \delta B \rho\right. \\
& \left.-\rho \delta U_{C}^{1}+\rho U_{C}^{2}+U_{A}^{1}+\rho U^{2}\right] \frac{d A}{d B} \\
& =
\end{aligned}
$$

Normally, standard envelope results would not apply here, but when $B=0$, both terms in square brackets are zero by the first-order conditions (13) and (14). The remaining term is positive by (14) and the fact that $0<\rho<1$. Thus consumers can be made better off with an infinitesimal annuity, and $R>$ $0, B=0$ cannot be a second-best market equilibrium.

The intuition behind the proof of Proposition 1 is that the moral hazard problem, which consists of the fact that consumers ignore changes in the cost of inframarginal units of annuity benefits, B, which are induced by their own health behavior, is negligible when the level of benefits is small. We now characterize the two possible types of second-best equilibria in turn.

(a) Second-Best Markets when $R=0$

Suppose that moral hazard problems are not particularly severe, and that as a result, the levels of annuity coverage of fered by competitive markets are not so low as to induce individuals to supplement annuities with private saving. Then the second-best market equilibrium can be found by maximizing (12) with respect to $A$ and $B$ only, subject only to (13), with $R=0$. The first-order conditions for a maximum of this problem are (using (13) to eliminate some terms): 


$$
\begin{aligned}
& \text { A: }-U_{C}^{1} \delta B \rho^{\prime}+\theta_{A} \Delta_{A}=0 \\
& \text { B: }-\rho \delta U_{C}^{1}+\rho U_{C}^{2}+\theta_{A}\left\{\rho \delta\left[U_{C C}^{1} p-U_{A C}^{1}\right]+\rho U_{C}^{2}\right\}=0
\end{aligned}
$$

where $\theta_{A}$ is a Lagrange multiplier and $\Delta_{A}=U_{C C}^{1} p^{2}-2 U_{C A}^{1} p+u_{A A}^{1}+p^{1} u^{2}+$ $\rho^{\prime} \delta B\left[U_{C C}^{1} p-U_{C A}^{1}\right]$, which must be negative for stability. ${ }^{14}$

The quantity multiplying $\theta_{A}$ in $(17)$, is negative by our "normality" assumptions. This in turn implies that the multiplier on constraint (13), $\theta_{A}$, is positive and allows us to derive:

Proposition 2 In actual second-best annuity markets, when the moral hazard problem is of the Case ( 1 ) ("cigarettes") type, and $R=0$, social welfare can always be improved by a marginal, fully-funded increase in either $A$ or $B$, holding everything else constant. This involves either increasing the death rate via greater consumption of hazardous goods (holding B fixed), or increasing retirement consumption holding $\rho$ fixed.

Proof The derivative of social welfare with respect to $B$ is given by the first two terms in (17) (See (10)). In the second-best equilibrium given by (17) the sum of these terms equals a positive number. Therefore, consumers would benefit from an increase in retirement consumption, B. A parallel argument applies to $A$ (and hence $\rho$ ), noting that in the second-best equilibrium, $-p u_{C}^{1}+u_{A}^{1}+\rho^{\prime} u^{2}=0$.

Thus at least in a "local" sense, annuities are underprovided and hazardous goods are underconsumed in a "second best" market equilibrium. 15 
The distortion affecting the second-best equilibrium can, in principle, be corrected by providing an optimal "Pigouvian" subsidy to cigarette consumption:

Proposition 3 In second-best annuity markets the first-best level of social welfare can always be achieved by providing a subsidy of amount $-\delta B p$ ' per unit of $A$, financed by lump-sum taxes.

Proof With the indicated subsidy, the unit price of $A$ would be $\tilde{p}=p+\delta B p$, and a lump-sum tax of - $\delta B p$ 'A would be levied. This would alter the secondbest problem to:

$\underset{A, R, B}{\operatorname{Max}} W=U^{1}[Y+\delta B \rho ' A-\rho(A) \delta B-\delta R-\tilde{p A}, A]+\rho(A) U^{2}[R+B]$

which reduces to the first-best maximand in (8). The constraint (13) on the second-best problem is transformed into the first-best first order condition (9). Thus the second-best problem collapses to the first-best problem. (Note that (14) becomes irrelevant as $R=0$ in the first-best).

Proposition 3 implies a policy recommendation which to many might seem abhorrent. This may reflect a prior belief that the net external benefits of improved health are positive. ${ }^{16}$ But it is not clear that this is the case. To a large extent individuals themselves capture the gains to improved health. Also, although increased health may have beneficial external effects on health insurance premia which are analogous to their harmful external effects on annuity premia, whether they actually do so depends on the relative effect of increased health on morbidity versus mortality. If better health 
increases the survival rate into the second period without substantially lowering the cost of providing medical care to each survivor, increased health has a net external cost through its effects on health insurance premia, which exacerbates the problem of excessive longevity considered in this paper. 17 More generally, Proposition 3 simply reflects the intuitive principle, demonstrated in Arnott and Stiglitz (1986) that in the presence of moral hazard (in their examples drunk driving or insufficient fire prevention) welfare can generally be improved via optimal commodity taxation (taxes on alcohol, or subsidies on fire extinguishers).

\section{(b) Second-Best Yarkets When $R>0$}

If underprovision of annuities due to moral hazard problems is sufficiently severe, consumers may choose to "top up" the annuities they are able to purchase with private saving. The second-best market annuity now maximizes (12) subject to both (13) and (14). The following proposition follows directly from the constraints (13) and (14) alone:

Proposition 4 In actual second-best annuity markets, when the moral hazard problem is of the Case (1) ("cigarettes") type and $R>0$, social welfare can always be improved by a marginal, fully-funded increase in either $A$ or $B$, with $R$ unchanged. Again, this would raise retirement consumption, or raise hazardous goods consumption and the death rate.

Proof The partial derivative of social welfare with respect to $R$ is $-\delta U_{C}^{1}+\rho U_{C}^{2}$, which is zero by constraint (14) in the second-best, $R>0$ equilibrium. 
The partial derivative of social welfare with respect to $B$ is $-\rho \delta U_{C}^{1}+\rho U_{C}^{2}$, (from (10)), which must be positive by (14) and the fact that $0<\rho<1$. The partial derivative of social welfare with respect to $A$, from ( 9 ), when constraint (13) holds, is just $-U_{C}^{1} \delta B_{p}{ }^{\prime}>0$.

Thus, as in the $R=0$ case, both $A$ and $B$ are, in a marginal sense, underprovided in the second-best equilibrium, while $R$ is at its "correct" level, given the levels of $A$ and $B .{ }^{18}$

3. Effects of Handatory Social Security

The effects of introducing mandatory, fully-funded public social security into a second-best market equilibrium depend on whether the level of B provided by the government is less or greater than that provided by private firms in the second-best equilibrium. In the first case, if the government has access to the same technology and information that private firms have, clearly its actions are inframarginal and have no effect on the equilibrium. Individuals simply reduce their private annuity purchases by a dollar for every dollar of public annuity provided. 19

Second, to see what happens when the government overprovides annuities, note first that it will be difficult for individuals to "undo" excessive public annuities through the purchase of negative annuities here. This is because a negative annuity would involve selling a claim to a part of one's future social security benefits, B, in return for consumption in period (1). In effect, as Yaari (1965) points out, negative annuities are life- 
insured loans in which (in this case) one's social security benefits are used as collateral. Such contracts are illegal in the U.S.: social security benefits cannot be pledged as collateral on loans. Even if this were not the case, such contracts could be very difficult to enforce.

When public annuities are excessive and negative private annuities are unavailable, retirement consumption of a given individual, $\mathrm{C}_{2}$, is just equal to the level of social security benefits, B, plus the proceeds from private saving, $R$. When $R=0$, this implies;

Proposition 5 In the "base case", when $R=0$, the introduction of any extramarginal, actuarially fair, social security plan, regardless of its size, will increase the level of retirement consumption, lower the consumption of hazardous goods, increase life expectancy, and lower the expected lifetime utility of the representative individual.

Proof Since individuals choose A optimally given $B$, if $R=0$, the level of $A$ they choose in the presence of any social security scheme will be characterized simply by the first-order condition for privately optimal $A$, in (13). Differentiating this expression with respect to $B$ under the assumption of full funding $(\rho \delta B=P)$ yields:

$$
\frac{d A}{d B}=-\frac{1}{\Delta}\left\{\rho \delta\left[U_{C C}^{1} p-U_{A C}^{1}\right]+\rho U_{C}^{2}\right\}
$$

which is negative, given our "normality" assumption. Since (18) holds for 
all levels of $B$, it characterizes the effects of large as well as small changes in $B$. The fact that individual welfare declines follows from the fact that extra-marginal social security, by definition, constitutes a departure from the maximum feasible utility given the individual-optimization constraint (13), which the social security system is subject to, just as private firms are. Other aspects of the proposition follow directly from the assumptions or from the above result.

Two interesting features of Proposition 5 and its proof are worth emphasizing. First, despite the fact that, due to moral hazard, annuities are under-provided in the absence of government intervention, Proposition 5 shows that a government-induced increase in annuities via a compulsory social security scheme, lowers social welfare. This is because the government is no better at handling moral hazard (unlike adverse selection) than the private market. Second, it is useful, for future reference, to think of the effect of social security, $B$, on health behavior, $A$, in (18) as composed of two components. One of these, $-\frac{1}{\Delta_{A}} \rho{ }^{\prime} U_{C}^{2}$, reflects the increased incentive to live longer due to social security's mandatory increase in second-period consumption. This tends to increase the survival rate, $\rho$. We call it the "substitution effect" of social security. The other effect, $-\frac{1}{\Delta_{A}} \rho \delta\left[U_{C C}^{1} \rho-U_{A C}^{1}\right]$, reflects the impact of the social security tax on the consumer in the first period. Since this tax makes people poorer in the first period, it also tends to lower their consumption of $A$, if $A$ is a normal good. The effect, in the "base case", is again to increase the survival rate, $p$. 
We call this the "income effect" of social security. In short, in the basic, "cigarettes" model, social security unambiguously raises longevity because its substitution effect (the increased incentive to survive) and its income effect (the fact that social security taxes lower the demand for, say, cigarettes) work in the same direction.

The effects of "excessive" social security on the equilibrium levels of $A$ and $R$ when $R>0$ are summarized in:

Proposition 6 In the base case, when $R>0$, the introduction of an actuarially-fair social security scheme which increases the annuity level, B, marginally above its second-best level will lower the consumption of hazardous goods, increase life expectancy, increase retirement consumption and have no first-order effects on the expected lifetime utility of the representative individual.

Proof See Appendix.

Thus, the effects of a marginal amount of social security on health are the same when $R>0$ as when $R=0$.

IV. OTHER HEALTH-RELATED GOODS

This section examines the differences between first-and second-best equilibrium as well as the effect of social security on longevity when the health-related good in question is of the Case 2 ("nutrition") or Case 3 ("doctors") type. For simplicity, we consider only the $R=0$ (no private saving) equilibrium throughout this section as well as the next. 20 


\section{Comparing First- and Second-Best Equilibria}

The fact that one result of the basic model essentially generalizes completely to Cases (2) and (3); both of which consider the consumption of "healthful" goods, $\rho$ '>0, is summarized in:

Proposition 7 In second-best annuity markets with a Case 2 ("nutrition") or Case (3) ("doctors") moral hazard problem, social welfare could always be improved by a marginal decrease in $A$, thereby decreasing consumption of the healthful good and raising the death rate.

Proof As noted in proposition 2, given constraint (13), the partial derivative of social welfare with respect to $A$ is just $-U_{C}^{1} \delta B \rho$ which is negative when $\rho^{\prime}>0$.

Thus, in second-best equilibrium, the healthful good is overconsumed (in a local sense). It is however, no longer possible to determine unambiguously whether annuities are under - or overprovided in the second-best equilibrium because the bracketed term multiplying $\theta_{A}$ in (19) is now ambiguous in sign for both Case (2) and (3). The intuition behind this is clarified when we consider the effect of mandatory public social security on health below.

Before doing so, however, it is worth noting that Proposition 3, concerning optimal fiscal remedies for these distortions applies equally to the case of "healthful" goods, $\rho^{\prime}>0$, as to that of "cigarettes". In the case of healthful A, however, rather than a subsidy being provided, an optimal 
Pigouvian $\underline{\operatorname{tax}}$, of amount $\delta \mathrm{Bp}^{\prime}$, is required to induce actual markets to mimic the first-best. (Tax revenue should be redistributed as a lump-sum transfer, $\left.\delta B_{p}^{\prime} A.\right)$

\section{Effects of Social Security}

Consider first a Case 2 - "nutrition" - good. For such a good $P^{\prime}>0, U_{A}>0$, and by "normality", $U_{A C} \geq 0$. Consumption of this good yields direct utility as well as increasing longevity, but has an external social cost (the induced increase in the equilibrium annuity premium) which is ignored by individual consumers. The effect of mandatory, excessive social security on health, given in (18), is now ambiguous in sign. The reason is that, while the income effect on $A,-\frac{1}{\Delta} \rho \delta\left[U_{C C}^{1} p-U_{A C}^{1}\right]$ is still negative (higher social security taxes make people worse off in the first period and reduce consumption of $A$ if it is normal), the substitution effect, $-\frac{1}{\Delta} \rho_{A} U_{C}^{2}$, is now positive (i.e. there is an incentive to invest in living longer by consuming more A). Thus, the income effects of social security taxes now counteract the substitution effect of social security on longevity, which is always positive, and could conceivably cause a reduction in longevity.

Finally, consider now a Case 3 - "doctors" - good, where $\rho '>0, U_{A} \leq$ 0 , and by "normality", $U_{A C} \leq 0$. Consumption of this good yields zero or negative direct utility, increases longevity, and again has an external social cost embodied in higher annuity premiums. The effect of mandatory social security on consumption of such goods, in (18), is again ambiguous, this time at least in part because the income effect, $-\frac{1}{\Delta_{A}} \rho \delta\left[U_{C C}^{1} p-U_{A C}^{1}\right]$ 
is itself ambiguous in sign, even under the strong assumption of "normality" used here. The only case in which it is not is when $p=0$. (Thus $A$ is a financially costless change in behavior, such as, for example, increased consumption of medical services under the comprehensive public health insurance schemes found in Canada, the U.K., and many other countries.). Then, given that $A$ is a "normal bad" in the sense that $U_{A C} \leq 0$, the effect of social security on health is unambiguous and positive because income and substitution effects are of the same sign.

The ambiguity in the effect of social security on health in Cases (2) and (3) also explains the ambiguity of the effect of a marginal increase in $B$ on social welfare in these two cases, noted earlier. Both arise from the fact that the bracketed quantity in (17) and (18), which is the effect of an additional unit of $B$ on the (private) marginal benefit of a unit of the health-related good, $A$, is ambiguous due to interactions between income and substitution effects.

\section{v. ACTUARIALLY "NON-FAIR" SOCIAL SECURITY}

Two types of situations in which individuals face social security plans which are not actuarially fair are as follows. First, as is well known, when a pay-as-you-go social security system is introduced into an over-lappinggenerations economy, the initial generation of old people receives a consumption windfall: they pay no social security taxes when young, yet receive social security benefits in the form of transfers from the next generation when old. If the individuals in this generation anticipate this windfall when young, they will modify their health investments in response to it. Second, if we allow for individual heterogeneity and progressive taxation in our model, then in any generation some individuals, who are relatively 
poor, will pay little or no social security taxes and yet receive substantial retirement benefits in the form of public annuities. Others will pay social security taxes in excess of the expected present value of their benefits. This section explores the effects of social security on the health investments of individuals who, for either of the above reasons, face an actuarially non-fair system. We consider in turn two cases: first, individuals who pay no social security taxes at all; and second, individuals who pay positive taxes which either exceed or fall short of their expected social security benefits.

The effects of social security on the health behaviours of individuals who pay no premiums can be easily analysed in the $R=0$ case of our model by setting $P=\rho(A) \delta B=0$ in (12) - (14). The results are summarized by:

Proposition 8 When $R=0$, and $P=0$, then regardless of the type of healthrelated good giving rise to the moral hazard problem, longevity always increases as a result of social security.

Proof When $R=P=0,(12)$ can be written:

$\operatorname{Max}_{A, B} W=U^{1}[Y-p A ; A]+\rho(A) U^{2}[B]$

Totally differentiating with respect to $B$ and rearranging yields:

$$
\frac{\mathrm{dA}}{\mathrm{dB}}=\frac{1}{\Delta_{A}} \quad \rho \mathrm{U}^{2}
$$

where $\tilde{\Delta}_{A}$ is negative by the second-order condition for the individual's maximization problem. Therefore $\frac{d A}{d B}$ has the same sign as $P^{\prime}(A)$; i.e. 
longevity always increases with $\mathrm{B}$.

Thus, much of the ambiguity in our model's predictions disappears when we focus on individuals (or generations) who pay no social security premiums but anticipate receiving benefits. This is because the period-1 income effects caused by social security taxes, noted earlier, do not exist here. Finally, consider now individuals who pay some social security taxes. If they bear more than their actuarially fair share of the tax burden, the income effects of social security discussed in section IV above are magnified. Therefore, in the cases where income and substitution effects work in the same direction (Case ( 1 ) goods, and Case ( 3 ) goods when $p=0$ ), social security must now a fortiori raise longevity. In the other cases the effects remain ambiguous, although the likelihood of a negative effect on longevity is clearly increased. For individuals whose taxes are positive but less than the expected value of their benefits, income effects are diminished relative to section IV but still in the same direction. In short, with strictly positive, actuarially non-fair taxes, the model's predictions are unambiguous in exactly the same circumstances as before, the only difference being the relative size of the income effects.

vI. OVBRLAPPING GENERATIONS

Suppose that social security was fully funded in every generation and that, both before and after its introduction there was no private saving for retirement consumption $(R=0)$. Then the effect of social security on the health and lifetime consumption profiles of individuals in all generations 
following its introduction would be the same. The same would be true for every generation but the first, or "impact" generation following the introduction of an unfunded social security system. Thus, aside from a "transitional" consideration which we have already examined (Section $v$ ), the explicit introduction of overlapping generations into our model is trivial when $R=0$. This section briefly explores two complications that arise in the $R>0$, overlapping-generations case. The first of these has to do with heterogeneity that is induced by stochastic longevity; the second concerns the long-run welfare effects of social security.

\section{1. "Induced" Heterogeneity}

Whenever private savings exist in this world $(R>0)$, there will be some "accidental" bequests, as in Davies (1981). More specifically, if a worker of dynasty $i$ in generation $t$ lives for a full two periods, he leaves no bequest, but if he does not survive into retirement, he leaves a bequest of $R_{i t}$, which is (presumably) shared among his descendants, and forms part of their endowment, $\mathbf{Y}_{i}, t+1$. As Abel (1985) has shown, this leads to a situation in which, even when dynasties are identical in their underlying characteristics, heterogeneity in income emerges as a result of the actual number of one's recent ancestors who survived for a full two periods. The more "early deaths" that have recently occurred in a dynasty, the better endowed its current members will be.

Now, given any individual's endowment, $Y_{i t}$, the predictions of the previous sections of the paper regarding the effects of social security on 
health and consumption patterns are all still valid here. It is important to note, however, that whenever $R>0$, social security also has an additional effect not noted earlier: to the extent that it reduces private savings, $R$, it will equalize the endowments of individuals, especially after several generations have passed. This process has been carefully analysed by Abel (1985) in the absence of moral hazard, and is not modelled formally here, for the sake of brevity.

\section{Long-Run Welfare Effects of Moral Hazard and Social Security}

The fact that, whenever $R>0$, accidental bequests occur, also has important implications for the long-run welfare effects of moral hazard and of social security that are not captured by considering a single generation in isolation. This is because, from a single generation's point of view, the accidental bequests they leave are pure "waste". In an overlapping-generations context the bequests are not pure social waste since they form part of the next generation's income. This can have quite striking implications for steady-state welfare.

For example, consider first the welfare implications of moral hazard, i.e. of the fact that nonaltruistic individuals ignore the external benefits of private saving in an overlapping-generations world. Recall that when moral hazard is not severe, $R=0$ will prevail in market equilibrium. But if moral hazard is more severe, the quantity constraints on $B$ that arise in second-best annuity contracts may induce individuals to "top up" their private annuity benefits with some private saving $(R>0)$. Thus it seems possible that severe moral hazard could have beneficial long-run effects by inducing people to undertake some private saving. This possibility may be an interesting one to explore in future work on this topic. 
Now consider the welfare effects of introducing social security into a world characterized by moral hazard. In an overlapping-generations world, it is now possible that the first-best, steady state policy, unlike before, may have $R>0 .{ }^{21}$ (A high interest rate and low population growth rate are conducive to this). In such a case social security, to the extent that it replaces private saving, will have an additional welfare cost not noted in previous sections: the decline in accidental bequests induced by social security impoverishes future generations. This is of course a well-known issue in the social security literature. (See, for example Kotlikoff et al (1983, 1984) for a recent summary of relevant results). The contribution of the present paper to this literature is to point out that social security may have welfare effects that operate through changes in individual behavior other than in the changes in savings rates analysed there.

\section{vII. CONCLUSIONS}

The goal of this paper was to analyse the effects of certain main elements of recent U.S. public policy (and their counterparts elsewhere) on peoples' longevity. To do so, we developed a simple life-cycle model of optimal consumption of health-related goods and analysed the effects of one particular policy-social security-on individuals' optimal (expected) longevity. We found that the effects of social security on health are likely to vary across types of individuals as well as across types of health-related goods. More specifically, social security has an effect in this model on all individuals for whom it is "extramarginal", i.e. who purchase no private annuities to supplement their social security benefits. Given this restriction, then regardless of the type of health-related good considered the effect of social security on health is always positive and unambiguous for 
individuals who pay no social security taxes. For individuals who pay positive social security taxes, the effect of social security on longevity is unambiguously positive in two cases: first, for all goods like cigarettes which increase current utility but lower life expectancy, and second, for financially costless behavioral changes such as exercising more, switching from high-to-low-tar cigarettes, or consuming more health care in a country (such as Canada or the U.K.) where it is free.

The positive implications of our model, we would argue, are consistent with the results of recent empirical work. There are many studies which have found a significant positive effect of anticipated social security and pension benefits on the retirement probability. An obvious part of the explanation is simply that higher social security benefits and pensions reduce the financial cost of retiring. However, if, as suggested by Wolfe (1985), retirement is itself a form of investment in health, the increased retirement probability may partly be due to an impact of annuities on health behavior.

More direct evidence comes from Anderson and Burkhauser (1985) and Sickles and Taubman (1986) which both estimate simultaneously the determinants of retirement and health for older men. Anderson and Burkhauser, using mortality and self-reported health states as alternative indicators of health, found positive but insignificant effects of social security wealth on health. Sickles and Taubman formed an integrated health status variable on the basis of mortality and self-reported health, and found a significant positive effect of both social security benefits and pension income on health. This is entirely consistent with our expectation that the impact of social security on most people will be to increase longevity. 
The likelihood of induced increases in longevity in the current model is not associated with a welfare improving role of social security. In fact, in all cases examined the effects of actuarially fair social security on lifetime expected utility were zero or negative. The reason is that the model provides no rationale for social security. The sole imperfection we study, moral hazard in annuity markets, affects social security schemes just as much as private insurers. In a more general model, with other imperfections (e.g. adverse selection), it is possible that social security could play a welfareimproving role. The normative implications of our model must therefore be handled with some care, but should not be ignored.

The model used in this paper could be extended in a number of relatively straightforward ways. One would be to analyze other policies such as government subsidization, through the tax system, of private pensions, and the provision of public health insurance. Such policies seem likely to raise longevity as well, but are likely to have a different incidence than social security. For example, subsidization of private pensions (which typically take the form of an annuity) is likely to affect the health investments of the very group - those who purchase private annuities in addition to their social security benefits - that is unaffected by the social security system. These policies can be analysed via minor modifications to the current model. A second extension involves refining the time structure of the current model, which as it stands does not allow the possibility that, for example, individuals may continue to make effective investments in health after they begin receiving social security. This latter possibility could be empirically very important, especially for the first generation of old people to receive social security benefits. Allowing an endogenous date of retirement might also have an interesting effect, since it would introduce an interaction 
between the twin moral hazards of earlier retirement and increased longevity. A third extension involves incorporating families into the analysis. As Kotlikoff et al. $(1981,1983,1984)$ have pointed out, families may play an important role in the private provision of annuities. It is tempting to ask whether this is partly because moral hazard is less of a problem within families than elsewhere. If so there could well be important consequences for the impact of social security on health. 


\section{APPENDIX: Proof of Proposition 6}

Proof The statement about expected utility follows simply from the fact that B maximizes (12) subject to (13) and (14). Any small departure from that level of $B$ which continues to satisfy the constraints must therefore have a negligible impact on welfare, W. (Larger departures of course reduce W.)

Now consider the implications of this property for small changes in $B$ to which individuals in the economy respond by choosing levels of $A$ and $R$ according to (13) and (14). Totally differentiating (12) gives (using (13) and (14) to simplify, yields:

$$
\frac{\partial W}{\partial B}=-\rho \delta U_{C}^{1} \frac{d A}{d B}-\rho\left[\delta U_{C}^{1}-U_{C}^{2}\right]=0
$$

Solving for $\frac{d A}{d B}$,

$$
\frac{d A}{d B}=\frac{-\rho\left[\delta U_{C}^{1}-U_{C}^{2}\right]}{\rho{ }^{\prime} \delta U_{C}^{1}}<0
$$

where the term $\left[\delta u_{C}^{1}-u_{C}^{2}\right]$ is negative by (14). Therefore, consumption of the hazardous good will fall.

To derive the effect of social security on retirement consumption, $R+$ B, totally differentiate (13), yielding:

$$
\Delta_{A} \mathrm{dA}+\mathrm{EdR}+\mathrm{FdB}=0
$$

where $E=\delta\left[U_{C C}^{1} p-U_{A C}^{1}\right]+\rho U_{C}^{2}<F<0$ 
and $F=\rho \delta\left[U_{C C}^{1} p-U_{A C}^{1}\right]+\rho^{1} U_{C}^{2}<0$.

Solving for $\frac{\mathrm{dR}}{\mathrm{dB}}$ gives

$$
\frac{d R}{d B}=\frac{-F-\Delta \frac{d A}{A B}}{E}
$$

which in turn implies

$\operatorname{sign} \frac{d(R+B)}{d B}=-\operatorname{sign}\left\{E-F-\Delta \frac{d A}{d B}\right\}>0$

i.e., retirement consumption rises with $B$.

Q.E.D. 


\section{NOTES}

1. Between 1941 and 1981, the 1ife expectancy of white U.S. males increased from 62.8 to 71.0 years. White female life expectancy increased even more, from 67.3 to 78.5 years. (Figures are from Information Please Almanac, Atlas and Yearbook (1985), p. 780.)

2. Changes in the retirement age and in fertility (which affects the ratio of old to young) are also important contributors to these funding problems.

3. A different kind of moral hazard - concerning essentially the age of retirement - is modelled by Diamond and Mirrlees (1978).

4. Social security can of course be welfare-improving if the only imperfection is adverse selection in annuity markets. We also point out in the paper, that although the effect is ambiguous, social security could help to offset the problem of moral hazard in health insurance markets.

5. A third method, not analysed here, would involve using family annuity markets, as in Kotlikoff and Spivak (1981) and Kotlikoff, Shoven and Spivak (1983, 1984). The probable effects of introducing such markets are discussed in footnote 19.

6. $R<0$ in this model means an individual can obtain a loan which must be repaid only if he survives, but which does not carry a "load" premium to compensate the lender for the probability of default. Clearly any firm which offered such a contract would lose money.

7. In the current model, this is primarily because the individual chooses, essentially, two "actions" - the amount of second-period consumption and the probability of survival into the second period. While "forcing 
contracts" can be used to induce exactly the "correct" amount of second-period consumption, the survival probability would still be inefficiently selected by the individual.

8. The first order condition and complementary slackness conditions for $\mathrm{A}_{2}$ can be written:

$\rho\left(A_{1}\right) \cdot\left\{-U\left(x_{2}, A_{2}\right) p+U_{A}\left(x_{2}, A_{2}\right)\right\}+\Phi_{2}-\bar{\phi}_{2}=0$

$\Phi_{2} A_{2}=0$

$\bar{\phi}_{2}\left(\bar{A}_{2}-A_{2}\right)=0$

where $\Phi_{2}$ and $\bar{\phi}_{2}$ are multipliers on the two inequality constraints involving $A_{2}$. These conditions indicate that the optimal level of $A_{2}$ is either on a boundary (in which case $A_{2}=0$ or $A_{2}=\bar{A}_{2}$ ), or is given by the condition $U_{x}\left(x_{2}, A_{2}\right) p=U_{A}\left(x_{2}, A_{2}\right)$. In either case, the optimal level of $A_{2}$ is always independent of $A$, and hence of $A_{1}$. Therefore, optimal utility conditional on surviving in the second period is also independent of $A_{1}$, and can be represented by the indirect utility function $U^{2}(R+B)$, which must be strictly concave and increasing in its argument. Also, by our earlier assumption on $U, \frac{\partial U^{2}}{\partial(R+B)} \rightarrow \infty$ as $(R+B) \rightarrow 0$. 
9. Any health-related activity that has a negative financial cost (e.g. working on a more dangerous job for more money) can clearly be handled in the model by denoting $A$ as the negative of that activity level.

10. If $p=0$, then Case 3 is formally identical to Case 1 and of course yields the same predictions. Otherwise they are distinct, as section IV shows.

11. This latter case, as well as some of the others mentioned is an example where $U_{A}^{1}=0$ seems natural.

12. The formulation in (8) assumes, for convenience, that firms can observe individuals' private savings decisions (i.e. the level of $R$ ) as well as the level of $A$. The equilibrium levels of $A, B$ and $R$ under this assumption are the same as if $A$ and $B$ were both observed by firms, but $R$ was not. To see this, simply derive the equilibrium when $R$ is chosen optimally by individuals, given the contractual levels of $A$ and $B$, and note that the constraint on $R$ implied by individual optimization will in general be nonbinding.

13. See note 12 .

14. Suppose that, for any given level of annuity benefits, B, market equilibrium was established via the following "tatonnement" process. Given an arbitrary initial level of $A$ and an actuarially fair annuity premium at that level of $A$, each consumer evaluates his or her private marginal benefit of $A$, given in (6). If this is positive, each consumer increases his consumption of A by a small amount (and conversely). This establishes a new level of A for all consumers in the market, and firms will adjust the annuity premiums they charge (P) to maintain actuarial fairness. 
Given the new $A$ and $P$, the process now repeats itself until the net private marginal benefit of $A$ is zero. In this world, an equilibrium will be stable if and only if $\Delta_{A}$, which gives the derivative of the net private marginal benefit of $A$ with respect to the level of $A$ in an actuarially fair annuity market, is negative. A sufficient condition for $\Delta_{A}<0$ is $\frac{\partial}{\partial A}(\rho \delta B+p A)=\rho \delta B+p>0$. In other words, a government-mandated increase in consumption of hazardous goods, A, must not make consumers financially richer by lowering the actuarially fair annuity premium more that it raises expenditures on hazardous goods (say cigarettes). This seems reasonable.

15. It is perhaps worth noting that this is not necessarily true globally (i.e. $B$ and $A$ are not both necessarily below their first-best levels); to prove this appears to require stronger assumptions than we have used.

16. It has also been pointed out to us that health might be regarded as a "merit good", that is a good which is under-consumed because individuals do not realize its true benefits, or are not maximizing. We have nothing to say about what might happen in a non-optimizing framework. On the former point, there is some evidence that on average, people estimate accurately the health consequences of behaviors like smoking. (See, e.g. Ippolito and Ippolito, 1984.)

17. It would be straightforward to generalize the current model to deal with morbidity as well as mortality. A natural assumption would be that there is some probability of becoming sick in each period, which is positively affected by $A$ if $\rho^{\prime}<0$, and negatively affected if $\rho^{\prime}>$ 0 . If health insurance insured against the costs of dealing with bouts 
of illness, and illness were only possible in the second period, the effect of health investment on expected remedial health care would be negative only if the proportional rise in $\rho$ was less than the percentage decline in the probability of becoming ill (in absolute value). More general models would embody the same essential ambiguity. In this context it is worth noting that one view is that recent increases in longevity have been accompanied by little reduction in age-specific morbidity. See Manton (1982).

18. This highlights the distinction between local and global welfare comparisons. Clearly, because the first-best level of $R$ is zero, $R$ is globally too high in the second-best equilibrium when $R$ is positive. At the same time, marginal decreases in $R$, holding $A$ and $B$ fixed at their second-best levels, will have no first-order effects on welfare.

19. If annuities were provided by families rather than firms, and if (as seems reasonable) we assume that within-family annuity markets are less subject to moral hazard than other annuity markets (because family members find it easier to monitor each others' health behaviors), this neutrality would not hold. Instead, even when the level of public social security provided is in some sense less than the annuity level families would choose for themselves, aggregate health will change when social security is introduced because a market with less moral hazard is being displaced by one with more. Family members, rather than agreeing on (and enforcing) reasonable limits on each other's health investments, can now "conspire" together against the government.

Another relevant consideration is that the risk-spreading capabilities of family annuity markets are less than those of large private firms or of society as a whole. 
20. Note that Proposition 1 still applies in Cases 2 and 3 , so there is no need to consider any cases where $B=0$. The $R>0$ case may occur, but is omitted for brevity and simplicity.

21. An example of this is very easy to derive if we assume that the accidental bequests left by a given generation are divided equally among the next generation. Then, in the standard, two period overlappinggenerations model simple algebra shows the following. The optimal steady-state policy involves $R>0$ with no annuities or social security whenever the interest rate exceeds the population growth rate. This is because bequests operate like a "negative" unfunded social security system - i.e. they are transfers from the old to the young. When accidental bequests are not shared equally, the analysis is more complex due to the "induced" heterogeneity issue. 


\section{REFERENCES}

Abel, A. "Capital Accumulation and Uncertain Lifetimes with Adverse Selection," Harvard Institute of Economic Research discussion paper no. 1111, Nov. 1984.

Abel, Andrew B., "Precautionary Saving and Accidental Bequests", American Economic Review, 75 (4) (September 1985): 777-791.

Anderson, K.H., and R.V. Burkhauser, "The Retirement-Health Nexus: A New Measure of and Old Puzzle", Journal of Human Resources, XX, No. 3, Summer, 1985.

Arnott, R., F. Lewis, and N. Olewiler. "Cigarette Smoking and Quitting: A Life-Cycle Approach." mimeo, Queen's Univ., 1986.

Arnott, R., and J. Stiglitz "Moral Hazard and Optimal Commodity Taxation", Journal of Public Economics 29, Feb. 1986, pp. 1-24.

Auster, R., I. Leveson and D. Serachek. "The Production of Health: An Exploratory Study." Journal of Human Resources, Fall 1969, pp. 411-436.

Barer, M. L. et al. "Lifestyles, Linkages and Liabilities: Theory and Evidence Justifying Economic Incentives for Healthier Lifestyles" McMaster University, Program for Quantitative Studies in Economics and Population, research report no. 112, November 1984.

Becker, G. A Treatise on the Family. Cambridge, Mass: Harvard Univ. Press, 1981.

Berkowitz, M., P. Fenn, and J. Lambrinos "The Optimal stock of Health with Endogenous Wages" Journal of Health Economics, 1983, pp. 139-147.

Davies, James B., "Uncertain Lifetime, Consumption, and Dissaving in Retirement", Journal of Political Economy, 89 (3) (June 1981): 561-577. 
Diamond, P. A. "A Framework for Social Security Analysis", Journal of Public Economics 8, 1977, pp. 275-298.

Diamond, P. and J. Mirrlees. "A Model of Social Insurance with Variable Retirement" Journal of Public Economics, Dec. 1978, pp. 295-336.

Eckstein, Zvi; Eichenbaum, Martin; and Peled, Dan. "Uncertain Lifetimes and the Welfare Enhancing Properties of Annuity Markets and Social Security", Journal of Public Economics, (26) (1985): 303-326.

Feldstein, M. S. "Social Security and Savings: the Extended Life Cycle Theory", American Economic Review, May 1976, pp. 77-86.

Grossman, M. "On the Concept of Health Capital and the Demand for Health", Journal of Political Econony, March/April, 1972, pp. 223-55.

Hamermesh, D. and Soss, Neal. "An Economic Theory of Suicide", Journal of Political Economy, 82 (Jan./Feb. 1974): 83-98.

Harris, J. "Taxing Tar and Nicotine," American Economic Review, June 1980, pp. 300-311.

Information Please Almanac, Atlas and Yearbook; 38th ed. Boston: Houghton Mifflin, 1985.

Ippolito, P.M. and R.A. Ippolito, "Measuring the Value of Life Saving From Consumer Reactions to New Information", Journal of Public Economics, $25(1 / 2)$, November 1984: 53-81.

Kotlikoff, L, J. Shoven, and A. Spivak. "Annuity Markets, Savings, and the Capital Stock", NBER working apper no. 1250, 1983.

Kotlikoff, L., J. Shoven, and A. Spivak. "The Effects of Annuity Insurance on Savings and Inequality" NBER working paper no. 1403, 1984.

Kotlikoff, L., and A. Spivak. "The Family as an Incomplete Annuities Market", Journal of Political Economy, April 1981, pp. 372-391. 
Lewit, E., and D. Coate. "The Potential for Using Excise Taxes to Reduce Smoking," Journal of Health Economics 1982, pp. 121-145.

Manton, K.G., "Changing Concepts of Morbidity and Mortality in the Elderly Population", Milbank Memorial Fund Quarterly, 60, No. 2, 1982.

Marin and Psacharopoulos, "The Reward for Risk in the Labor Market", Journal of Political Economy, August 1982.

Muurinen, J.M. "Demand for Health: A Generalized Grossman Model" Journal of Health Economics, 1982, pp. 5-28.

Sickles, C., and P. Taubman, "An Analysis of the Health and Retirement Status of the Elderly", Econometrica, Nov. 1986, pp. 1339-57.

Taubman, P. and S. Rosen. "Healthiness, education, and marital status," in V. Fuchs, ed. Economic Aspects of Health, Chicago: Univ. of Chicago Press, 121-40.

Wolfe, J.R. "A Hodel of Declining Health and Retirement" Journal of Political Economy, Dec. 1985, pp. 1258-1267.

Yaari, H.E. "Uncertain Lifetime, Life Insurance, and the Theory of the Consumer" Review of Economic Studies, April 1965, pp. 137-150. 